\title{
Care of older people with Cognitive Impairment or Dementia Hospitalized in Traumatology Units (CAREXDEM): a quasi- experiment
}

Claudia Casafont ${ }^{1}$, Ester Risco ${ }^{2}$, Mercè Piazuelo ${ }^{3}$, Marta Ancín-Pagoto ${ }^{4}$, José Luis Cobo-Sánchez ${ }^{5}$, Montserrat Solís-Muñoz ${ }^{6}$ and Adelaida Zabalegui ${ }^{*}$ (D)

\begin{abstract}
Background: In our context, as in other European countries, care of patients with cognitive disorders or dementia still represents a major challenge in hospital settings. Thus, there is a need to ensure quality and continuity of care, avoiding preventable readmissions, which involve an increase in public expenses. Healthcare professionals need to acquire the necessary knowledge and skills to care for hospitalized patients with cognitive disorders and dementia.

Methods: A quasi-experimental design with repeated observations, taken at baseline, post-intervention, and at one and three months post-intervention, in people hospitalized with cognitive disorders or dementia. The study will be carried out in four general hospitals in Spain and will include 430 PwD and their caregivers. The intervention was previously developed using the Balance of Care methodology where nurses, physicians, social workers and informal caregivers identified the best practices for this specific care situation. We aim to personalize the intervention, as recommended in the literature. The study has an innovative approach that includes new technologies and previous scientific evidence. Valid, reliable instruments will be used to measure the intervention outcomes. Quality of care and comorbidity will be analyzed based on the use of restraints and psychotropic medication, pain control, falls, functional capacity and days of hospitalization. Continuity of care will be measured based on post-discharge emergency hospital visits, visits to specialists, cost, and inter-sectorial communication among healthcare professionals and informal caregivers. Statistical analysis will be performed to analyze the effect of the intervention on quality of care, comorbidity and continuity of care for patients with dementia.
\end{abstract}

Discussion: Our aim is to helping healthcare professionals to improve the management of cognitive disorders or dementia care during hospitalization and the quality of care, comorbidity and continuity of care in patients with dementia and their informal caregivers. Moving towards dementia-friendly environments is vital to achieving the optimum care outcomes.

(Continued on next page)

\footnotetext{
* Correspondence: azabaleg@clinic.cat

7 Vice director of Research and Education in Nursing in Hospital Clinic Barcelona, Assistant lecturer Universitat de Barcelona, Escala 1 planta 7. Villarroel 170, 08036 Barcelona, Spain

Full list of author information is available at the end of the article
}

(c) The Author(s). 2020 Open Access This article is licensed under a Creative Commons Attribution 4.0 International License, which permits use, sharing, adaptation, distribution and reproduction in any medium or format, as long as you give appropriate credit to the original author(s) and the source, provide a link to the Creative Commons licence, and indicate if changes were made. The images or other third party material in this article are included in the article's Creative Commons licence, unless indicated otherwise in a credit line to the material. If material is not included in the article's Creative Commons licence and your intended use is not permitted by statutory regulation or exceeds the permitted use, you will need to obtain permission directly from the copyright holder. To view a copy of this licence, visit http://creativecommons.org/licenses/by/4.0/. The Creative Commons Public Domain Dedication waiver (http://creativecommons.org/publicdomain/zero/1.0/) applies to the data made available in this article, unless otherwise stated in a credit line to the data. 


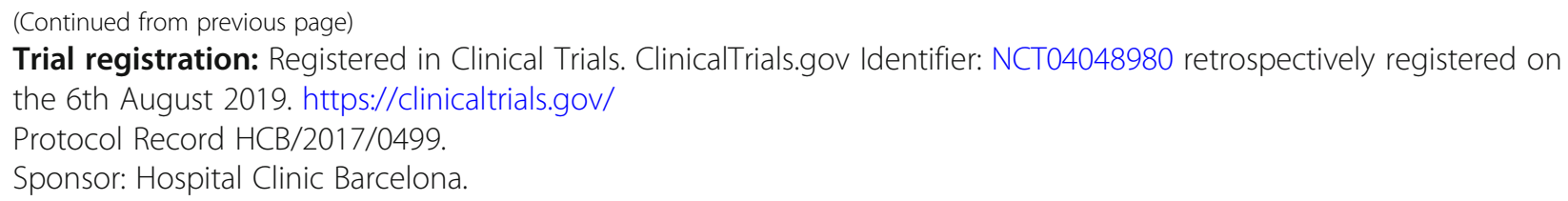

Keywords: Dementia, Intervention, Elderly, Nursing care, Femur fracture, Continuity of patient care

\section{Background}

Acute hospital care of patients with dementia (PwD) needs to be redesigned so that it is tailored to their needs and those of their caregivers. This would allow improvements to care received and continuity of care, along with a reduction in costs.

Fifty million people worldwide live with dementia. Dementia has still no cure and is linked to aging [1]. According to the National Statistics Institute in Spain (INE), it is expected that $29.4 \%$ of the total population will be 65 or older in 2068 [2]. As dementia progresses, cognitive and functional levels deteriorate until PwD depend completely on a caregiver [3]. An informal caregiver (IC) is a person who assists or looks after another person affected by an impairment or disability that prevents or impedes normal performance of daily-life activities or social relationships without receiving any income. Usually, ICs are women within the family between 45 and 70 years old [4]. Informal care costs in Spain represent a growing economic burden [5], higher than formal care costs.

Dementia is one of the main causes of incapacity in the elderly, requiring frequent health and social service use. In recent years, the number of hospitalized patients with dementia has increased, although $25 \%$ of these patients are not formerly diagnosed [6]. For this reason we classify included patients as those with dementia or cognitive impairment.

In Spain, about 50,000 to 60,000 femur fractures occur every year, with a hospitalization rate of 100 admissions per 100,000 inhabitants/year [7]. A study showed that $38.5 \%$ of patients older than 70 admitted due to a femur fracture were $\operatorname{PwD}[8]$, similar to findings by Mosk's et al. [9]. Hence, we focus on this population group, due to the high incidence of dementia and femur fractures seen in the Spanish National Health System.

When a PwD is admitted to a fast-paced, noisy acute hospital, the unknown environment can trigger disorientation and agitation, where distress is also experienced due to disruption of normal routine [10]. This can be challenging for nurses that are expert in the unit specialty, in this case traumatology, but are not specifically trained to look after PwD. Lack of training focused on care of PwD or cognitive impairment can cause professionals to feel incompetent and frustrated and lead to high levels of stress.
This can result in heightened clinical practice risk $[11,12]$. Additionally, the unpredictable nature of dementia means that PwD can show lucidity one day, or inability to follow instructions the next day, which can worsen the situation [13]. As such, educational interventions should focus on how staff identifies PwD experiences and shares knowledge on how to manage challenging behaviors through development of person-centered practices and focusing on priorities [14].

A study in the United Kingdom showed that $57 \%$ of hospitalized $\mathrm{PwD}$ presented aggressiveness, $42 \%$ had sleeping problems and 35\% suffered from anxiety [15]. To prevent delirium and aggressiveness in $\mathrm{PwD}$, we can act on triggers, modify the environment, foster psychosocial abilities or optimize resources. Furthermore, physical restraints are used to control agitation/aggressiveness when there is potential danger to the patient and his/her environment and he/she cannot be controlled with other measures (verbal or pharmacological). Restraints can only be used when other measures fail [16]. However, in Spain, $25 \%$ of hospitalized patients with moderate to severe dementia presenting agitation are physically restrained; one of the highest rates in countries in Europe [17].

Similarly, psychotropic medication administration is also higher in Spain than in any other European country, identified in 54\% of PwD [18]. Studies found an association between use of multiple psychotropic medications and a higher risk of fall injuries, hospitalizations and death. Non-pharmacological alternatives are safer and can impact positively in social economic burden and patient comfort [19].

Another important aspect to consider in care of hospitalized $\mathrm{PwD}$ is pain management. This can also be very challenging for nurses, especially when it comes to initiating pain assessment and adequate use of tools. Moreover, cognitive impairment limits the ability to communicate and describe pain [20].

Very few intervention studies are found in the literature and more research needs to be conducted to develop and assess educational programs to improve care of hospitalized PwD. Moreover, communication skills between multidisciplinary and intersectoral teams and patients and families need to be improved to ensure better global health services [21]. Furthermore, health professionals looking after PwD should have specific skills 
and knowledge to provide adequate care [22]. PwD are still stigmatized, and nurses should understand their needs and be empathic as with any other patients [10]. For example, training staff in nursing homes through didactic sessions and case discussions given by experts in neurology and geriatrics decreased the use of physical and chemical restrictions [23]. The same could be applied in hospital settings. The high vulnerability of hospitalized PwD underlines the need to confront this challenge continuously from a global perspective and the importance of conducting intervention studies in hospitalized PwD at the national and international level. Therefore, we propose to design, implement and assess a multidisciplinary, multifactorial educational intervention called "CAREXDEM", based on the Balance of Care model (BoC) [24], addressed to nurses looking after hospitalized PwD in traumatology units.

The outlined protocol follows the research group approach to care of $\mathrm{PwD}$, highlighting the following studies: 1) RightTimePlaceCare for PwD and their caregivers (RTPC), financed by the EU (grant agreement 242,153) [17]. This study compared care of PwD in eight countries to identify best practices related to quality of care and quality of life of PwD and their carers. 2) The study "Information, training and Social support" (INFOSA) [25], for caregivers of dependent, elderly patients admitted to hospitals, financed by FIS grant (PI 09/00111) and 3) Experimental study INFOSA-DEM for caregivers of PwD financed by "La Marató de la TV3" Exp. 20,144,410 (Reference pending for publication in JAN). We also draw on the experience and knowledge generated by the European study on empowerment of patients admitted to traumatology units for surgery [26] that demonstrates how greater satisfaction with received care promotes better postsurgical recovery.

We expect to decrease comorbidity and improve quality and continuity of care of hospitalized PwD with proximal femur fracture requiring surgery, along with minimizing costs.

\section{Aims and objectives}

The aim of this study is to design, implement and assess the effectiveness of an intervention program for nurses looking after hospitalized patients with proximal femur fracture and dementia or cognitive impairment in acute hospitals and measure its impact in terms of quality of care, morbidity reduction, improvement of continuity of care, and cost reduction. It has 4 objectives:

1) To develop and implement a program for care of hospitalized patients with dementia or cognitive impairment (CARExDEM) with a multidisciplinary consensus model (Balance of Care).
2) To assess the impact of the intervention regarding quality of care and comorbidity in these patients (physical restraints, psychotropic medication, falls, functional capacity, pain assessment, length of hospital stay and number of readmissions).

3) To evaluate the impact of the (CARExDEM) intervention with respect to to continuity of care (informal caregiver reaction, multidisciplinary and intersectoral communication) in global patient care.

4) To assess the impact of the intervention CARE $x$ DEM regarding the economic costs of hospital and community care at 1 and 3 months post discharge.

5) To evaluate nurses' knowledge before and after implementing CARExDEM.

\section{Methods}

\section{Design}

This is a quasi-experimental pre-post test, longitudinal, multicenter study. Data will be collected at hospital admission, discharge, 1 month follow-up (when visiting physician for surgery follow-up) and 3 month follow-up (See Fig. 1 for study overview).

\section{Setting and participants}

The study will be conducted in four traumatology units at high technology public hospitals across Spain. The autonomous communities included are Catalonia (Hospital Clinic Barcelona), Madrid (Hospital Puerta de Hierro Majadahonda), Cantabria (Hospital Universitario Marqués de Valdecilla) and Navarra (Complejo Hospitalario de Navarra). The study will be held in a 3-year frame time, with control group data collection starting in in August 2018.

Participants will be PwD and their caregivers $(n=432)$, and healthcare professionals working in the traumatology unit $(n=85)$. Patients will be recruited consecutively in two groups from emergency department admissions for surgery (See Table 1):

- Control group: People with dementia or cognitive impairment hospitalized with proximal femur fracture under surgery and their informal caregivers receiving usual nursing care. The main aspects covered in usual nursing care include control of pain, mobility, drainage and wound assessment, mobilization and nutrition following the established guidelines for each hospital.

- Experimental group: People with dementia or cognitive impairment hospitalized with proximal femur fracture under surgery and their informal caregivers receiving the intervention (CARExDEM).

- All healthcare professionals working in traumatology units (nurses, care assistants, physiotherapists, social workers and physicians) will answer an ad hoc 


\section{CARExDEM Study Overview}

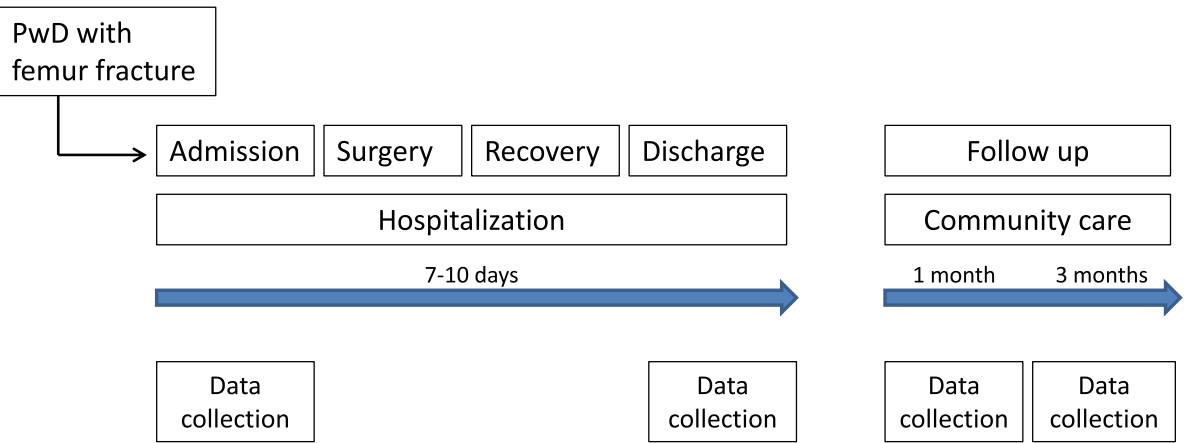

Fig. 1 Study Protocol Overview

questionnaire to assess knowledge in care of $\mathrm{PwD}$ before and after the intervention.

Inclusion criteria:

a) Patients older than 65 hospitalized for surgery; a score of 5 or less in the Short Portable Mental Status Questionnaire (SPMSQ) test [27]; providing signed informed consent; and with an informal caregiver able to understand the recommendations of health professionals.

b) Informal caregivers: The person in charge of looking after the patient with dementia, living with him/her or visiting at least three times per week at home or at a nursing home; providing signed informed consent.

Exclusion criteria: Patients younger than 65; those with psychiatric symptoms or Korsakoff's syndrome, absence of signed informed consent.

\section{Measurements}

Measures for PwD

All questionnaires selected are valid, reliable and widely used among studies with PwD. All questionnaires had previously been translated into Spanish and authors gave permission for their use. The whole questionnaire can be completed in $45 \mathrm{~min}$ (for patient questions) and $15 \mathrm{~min}$ (for informal caregivers). Table 2 represents a summary of all tests included and their main features.

Measurements performed in PwD include use of mechanical restraints, pain management, number of falls, comorbidity (Charlson Index) [28, 29], nutritional assessment (MNA) [30, 31], pressure ulcers, psychotropic medication administration, functional capacity (Barthel) [32, 33], length of stay and readmissions, behavior (NPI) [34, 35], activities of daily living (Katz) [36, 37], and pain assessment for PwD (PAINAD) [38, 39].

Continuity of care: Nursing discharge planning and information given to patients and families.

Table 1 Data collection summary. (HCB Hospital Clinic Barcelona, HPHM Hospital Puerta Hierro Majadahonda, HMV Hospital Universitario Marqués de Valdecilla; CHN Complejo Hospitalario de Navarra)

\begin{tabular}{|c|c|c|c|c|}
\hline & $\begin{array}{l}\text { Data } \\
\text { collection } 1\end{array}$ & $\begin{array}{l}\text { Data } \\
\text { collection } 2\end{array}$ & $\begin{array}{l}\text { Data } \\
\text { collection } 3\end{array}$ & $\begin{array}{l}\text { Data } \\
\text { collection } 4\end{array}$ \\
\hline \multirow{4}{*}{$\begin{array}{l}\text { Control Group } \\
\text { People with dementia or cognitive impairment admitted to traumatology units } \\
\text { receiving usual care }\end{array}$} & $\mathrm{HCB}(n=54)$ & $\mathrm{HCB}(n=54)$ & $\mathrm{HCB}(n=54)$ & $\mathrm{HCB}(n=54)$ \\
\hline & $\mathrm{HPHM}(n=54)$ & $\mathrm{HPHM}(n=54)$ & $\operatorname{HPHM}(n=54)$ & $\mathrm{HPHM}(n=54)$ \\
\hline & $\operatorname{HMV}(n=54)$ & $\operatorname{HMV}(n=54)$ & $\operatorname{HMV}(n=54)$ & $\mathrm{HMV}(n=54)$ \\
\hline & $\mathrm{CHN}(n=54)$ & $\mathrm{CHN}(n=54)$ & $\mathrm{CHN}(n=54)$ & $\mathrm{CHN}(n=54)$ \\
\hline \multicolumn{5}{|l|}{ INTERVENTION: CARExDEM Program } \\
\hline \multirow{4}{*}{$\begin{array}{l}\text { Experimental Group } \\
\text { People with dementia or cognitive impairment admitted to traumatology units } \\
\text { receiving the intervention }\end{array}$} & $\mathrm{HCB}(n=54)$ & $\mathrm{HCB}(n=54)$ & $\mathrm{HCB}(n=54)$ & $\mathrm{HCB}(n=54)$ \\
\hline & $\operatorname{HPHM}(n=54)$ & $\mathrm{HPHM}(n=54)$ & $\operatorname{HPHM}(n=54)$ & $\mathrm{HPHM}(n=54)$ \\
\hline & $\operatorname{HMV}(n=54)$ & $\operatorname{HMV}(n=54)$ & $\operatorname{HMV}(n=54)$ & $\mathrm{HMV}(n=54)$ \\
\hline & $\mathrm{CHN}(n=54)$ & $\mathrm{CHN}(n=54)$ & $\mathrm{CHN}(n=54)$ & $\mathrm{CHN}(n=54)$ \\
\hline
\end{tabular}


Table 2 Distribution of questionnaires for all data collection phases

\begin{tabular}{|c|c|c|c|c|c|}
\hline Questionnaires & Number of Items & Admission & Discharge & 1-month follow-up & 3-month follow-up \\
\hline \multicolumn{6}{|l|}{ PwD and IC } \\
\hline Inclusion and exclusion criteria & - & $\checkmark$ & & & \\
\hline Cognitive Assessment (SPMSQ) & 10 & $\checkmark$ & $\checkmark$ & & \\
\hline Clinical data and history & - & $\checkmark$ & & & \\
\hline Medication record & - & $\checkmark$ & $\checkmark$ & $\checkmark$ & $\checkmark$ \\
\hline PAINAD & 5 & $\checkmark$ & $\checkmark$ & $\checkmark$ & $\checkmark$ \\
\hline Morbidity (falls, pressure ulcers, restraints, etc.) & - & $\checkmark$ & $\checkmark$ & $\checkmark$ & $\checkmark$ \\
\hline Nutritional assessment (MNA) & $6+12$ & $\checkmark$ & & $\checkmark$ & \\
\hline Charlson Comorbidity index & 19 & $\checkmark$ & & & \\
\hline Barthel & 10 & $\checkmark$ & $\checkmark$ & $\checkmark$ & $\checkmark$ \\
\hline ADL (Katz) & 6 & $\checkmark$ & $\checkmark$ & $\checkmark$ & $\checkmark$ \\
\hline NPI-Q & 12 & $\checkmark$ & $\checkmark$ & $\checkmark$ & \\
\hline Satisfaction (PSS) & 11 & & $\checkmark$ & & \\
\hline Costs (RUD) & - & $\checkmark$ & & $\checkmark$ & \\
\hline Caregiver Reaction (CRA) & 24 & & & $\checkmark$ & \\
\hline Caregiver experience (IEXPAC) & 16 & $\checkmark$ & $\checkmark$ & $\checkmark$ & $\checkmark$ \\
\hline Follow -up (use of health and social services) & - & & & $\checkmark$ & $\checkmark$ \\
\hline
\end{tabular}

\section{Measures for informal caregivers}

Patient satisfaction with nursing care (PSS) [40].

Care reaction (CRA) [41, 42] measuring self-esteem, lack of family support, financial problems, interrupted schedules and health problems.

Continuity of care experienced from the IC's perspective (IEXPAC) [43].

Costs: Resource utilization in dementia (RUD), to assess costs of formal, informal and community care in PwD [44].

\section{Measures for healthcare professionals}

An ad hoc questionnaire will assess nurses' and other healthcare professionals' standards of care in PwD along with self-assessment on patient education prior to and following the intervention. Some open questions will identify barriers and facilitators in patient education and care.

\section{Data collection}

Data will be collected by trained interviewers at hospital admission (within $24 \mathrm{~h}$ ), on discharge, 1 month followup at the outpatient traumatology appointment and 3month follow-up (phone call). Questionnaires have been standardized in one document according to the collection phase. Questions will be responded to according to patient and caregiver data.

\section{Procedure}

The study will be conducted in 3 phases:
Pre-intervention stage: program design and control group data collection Intervention

Design of the CARExDEM intervention is based on results obtained from the European RightTimePlaceCare [17] study, where care of PwD and their caregivers was assessed in Europe using the Balance of Care methodology [24].

The research team organized two expert-panel meetings, inviting 20 healthcare professionals (nurses, physicians, physiotherapists, social workers and care assistants) with expertise in dementia, cognitive impairment and traumatology in hospitalization and primary care. They were divided into four groups and the research team provided each group with two clinical situations and a list of available resources and activities. The aim was to match the best resources to each situation to achieve the best care. The experts reached a consensus on the best care needed under each set of circumstances in relation to applicability, follow-up, population participation and cost/time saving. Results were validated in a second meeting with experts where activities were classified into five categories: study of basic care, organization, cognition, knowledge, safety, along with discharge planning. Intervention activities are included in Table 3.

Data will be collected for control group by trained interviewers. Subjects will be recruited by consecutive sampling on the first $24 \mathrm{~h}$ of ward admission.

Implementation of the CARExDEM intervention

Implementation will follow the Promoting Action on Research Implementation in Health Services (PARIHS) 
Table $\mathbf{3}$ Intervention activities

\begin{tabular}{|c|c|}
\hline Basic Care & $\begin{array}{l}\text { PAINAD scale (pain assessment) [38, 39], Braden scale (pressure ulcer assessment) [45], skin integrity assessment, nutrition } \\
\text { assessment [31], favoring night sleep (lights, noise, temperature...), minimizing physical restraints with verbal containments, } \\
\text { negotiating and using TOP5 tool [46]; a strategy to enhance communication and enhancing patient-centered care. }\end{array}$ \\
\hline Organization & Room placed next to nurses' station, visible signs for toilet and wardrobe, staff identification badges. \\
\hline Cognition & $\begin{array}{l}\text { Patients wearing own gowns/clothes, memory exercises, pleasant reminiscence objects (photographs, music...). Visible clocks and } \\
\text { calendars for time orientation. Volunteers will visit at least twice a week. }\end{array}$ \\
\hline Knowledge & Brochure will be developed for caregivers and families to provide hospitalization recommendations and discharge planning. \\
\hline Safety & $\begin{array}{l}\text { Falls risk and cognitive impairment identification, closed slippers, physiotherapy aids, placing reachable objects, bed in low } \\
\text { position, consider handrails and reachable bell. }\end{array}$ \\
\hline $\begin{array}{l}\text { Discharge } \\
\text { planning }\end{array}$ & Early discharge planning, social worker follow-up, community resources information, contact with primary nurse. \\
\hline
\end{tabular}

framework [47], taking into account the three key elements to achieve successful implementation; evidence, context and facilitation.

Prior to implementation, educational training will be given, following the same protocol in each hospital. Training will be provided on aspects such as use of physical restraints, psychotropic medication, falls, functional capacity and pain management according to best practices and clinical guidelines. To enhance adherence and raise awareness about the care model, the intervention will be supported with a checklist. This will summarize all activities to be delivered to the patient by category; basic care, organization, cognition; knowledge, safety and discharge planning. It will be completed every 3 days from admission by the day shift nurse responsible for each patient.

A pilot test will be conducted prior to implementation in each hospital. We will consider the opinions of experts and informal caregivers related to applicability, follow-up, population participation, and time/cost savings. Once the intervention is implemented, the research team will monitor closely to be aware of questions in case of doubts or barriers. Weekly meetings will be held to review nurses' training and to share their experiences with the research team.

\section{Follow-up and assessment of the CARExDEM implementation}

After implementation, data will be collected for the experimental group using the same instruments and organization as those for the control group. Weekly meetings will be held for follow-up and to provide support to the interviewers and ward staff. A data manager will input data into a database and results will be evaluated by an expert statistician. Results will be disseminated through journals and congresses.

\section{Statistical analysis}

Descriptive analysis will be used for baseline data. Categorical variables will be represented with absolute frequencies and percentages. For continuous variables, mean values, standard deviation or medians will be calculated. To study the effect of the intervention, analysis of co-variance will be carried out (ANCOVA), with Student's t-test for continuous variables and McNemar's test for categorical variables. Sensitivity will be analyzed to compare basal data of participants who complete the study with those who do not. Main outcome measures include quality of care and comorbidity (physical restraints, psychotropic medication, falls, functional capacity, pain assessment, length of hospital stay and number of readmissions); continuity of care (informal caregiver reaction, multidisciplinary and intersectoral communication) economic costs of hospital and community care and nurses' level of knowledge in acute care of PwD. Outcomes measured will assess longitudinal changes from all the collection phases; baseline (admission), discharge, 1 month and 3-month followup, comparing pre-intervention and post-intervention values. Confidence intervals of $95 \%$ will be calculated. Values of $p<0.05$ will be considered significant. Statistical analysis will be performed with R-3.2.3. for Windows. The research team will reflect on the analyzed data and issue a final report including the CARExDEM program with the required modifications identified following the implementation evaluation. This will ease the subsequent implementation of the program in other hospitals.

For the sample calculation, we estimated that a sample of 432 participants need to be included in the study, assuming an improvement in patients with pain around $50 \%$, with precision of $5 \%$, a confidence interval of 95 and $10 \%$ of dropouts. Only the research team and data manager will have access to data.

\section{Study progress}

Data collection for the control group started in July 2018 and is ongoing. So far, 173 patients have been recruited in control group. Multidisciplinary groups are currently working on the intervention at each hospital, following the BoC methodology. 


\section{Discussion}

This paper presents the study protocol for the CARExDEM program. This intervention aims to provide nurses with strategies for the management of PwD in acute care and to raise awareness of the importance of individualized care in these patients to improve continuity of care in exacerbated situations in PwD. Hospitals in Spain are still far from being environments prepared for PwD. Most focus on quick and efficient diagnosis and management of acute serious disease processes, whereas other countries are now restructuring their units to be more senior friendly.

The presentation of the comprehensive CARExDEM care management protocol for PwD is innovative as we have found no published interventions for these patients in hospital settings. There is a need to ensure continuity of care so patients can return to their setting with minimal disruption. Informal caregivers will also benefit from a smoother transition after hospital discharge.

The main limitation of the study is its scope of application. As it is a study carried out in specialized units, the results obtained cannot be generalized to the other wards in the hospital. To compensate this limitation, we have included 4 hospitals from different Autonomous Communities to broaden project development in different clinical settings. A strength of this study is the information that contributes to empowering patients, their caregivers and professionals and encourages policymakers and organizations to adapt hospital settings to the needs of PwD.

\begin{abstract}
Abbreviations
ADL: Activity of daily living; BoC: Balance of Care; CARExDEM: Care of persons with cognitive impairment or dementia hospitalized in acute hospitals; CHN: Complejo Hospitalario de Navarra; CRA: Caregiver reaction assessment; IC: Informal caregiver; IEXPAC: Instrument for evaluation of experience of Chronic Patients; HCB: Hospital Clinic Barcelona; HPH: Hospital Puerta Hierro Madrid; HMV: Hospital Marqués de Valdecilla; MNA: Mini-nutritional assessment; NPI-Q: Neuropsychiatric Inventory Questionnaire; OCDE: Organization for Economic Cooperation and Development; PARIHS: Promoting Action on Research Implementation in Health Services; PAINAD: Pain assessment in advanced dementia; PwD: Patient with dementia; PSS: Patient Satisfaction Scale; RTPC: RightTimePlaceCare Study; SPMSQ: Short Portable Mental Status Questionnaire; RUD: Resource utilization in dementia
\end{abstract}

\section{Acknowledgements}

TOP 5 is an initiative developed in the Central Coast Local Health District (CCLHD, NSW). The Clinical Excellence Commission has designed this toolkit to support the implementation and adoption of the TOP 5 concept within hospitals, Residential Aged Care Facilities and community facilities. The authors would like also to thank all the staff at traumatology units in the included hospitals for their cooperation and willingness to participate in the study.

\section{Sponsor}

This project is framed in the research group "Nursing Care of older people" from the Biomedic Research Institute August Pi i Sunyer (IDIBAPS) partner with Hospital Clinic Barcelona.

\section{Authors' contributions}

Protocol design: AZ, ER, CC. Work plan: CC, AZ " MA, JC MS. Balance of Care sessions development: CC, AZ, ER, MP. Validation of Balance of Care data: All authors. Intervention development: All authors. Validation of intervention: Being validated by all authors. Manuscript draft: CC, AZ. Revision of manuscript: All authors have read and approved the manuscript.

\section{Funding}

This study received a research grant from the Carlos III Institute of Health, Ministry of Economy and Competitiveness (Spain) with reference "PI17/ 01049", Co-funded by European Regional Development Fund. Carlos III Institute is a national reference centre for funding research projects and research networks on health sciences. The objective is to develop, encourage and strengthen research in the National Health System in Spain.

This project received a peer-reviewed approval from Carlos III Institute, which is involved in the follow up of the workplan annually according to the proposed aims and methodology. Also, funding is justified annually, as reports are presented explaining the expenses in relation to the given objectives.

\section{Availability of data and materials}

The data that support the findings of this study are available on request from the corresponding author, (AZ)

\section{Ethics approval and consent to participate}

This study is approved by the Clinical Research Ethical Committee at each hospital; Comité Ético Hospital Clinic Barcelona (HCB/2017/0499), Comité Ético de Investigación Hospital Puerta de Hierro Majadahonda de Madrid (H.U.P.H.: P.I.: 149/17), Comité Ético de Investigación Clínica de Cantabria IDIVAL (2017.241) and Comité de Ética Navarra (Pyto2017/39). Bearing in mind participants will present dementia or cognitive impairment, they will express their willingness to participate accompanied by a family member, caregiver or legal guardian. An information sheet will be provided to inform participants about the purpose of the study and a consent form will be signed by each participant prior to data collection. This study follows Declaration of Helsinki guidelines (World Medical Association, 2013). Participants will be able to withdraw from the study at any time. All data will be treated following UE Regulation 2016/679 of the European Parliament and Council of April 27th 2016 in relation to handling of personal data and the Organic Law 3/2018 of 5th December of Personal Data protection and digital rights warranty.

\section{Consent for publication}

Not applicable.

\section{Competing interests}

The authors declare that they do not have competing interests.

\section{Author details}

${ }^{1}$ Consultant Nurse in Research, Hospital Clinic Barcelona, Assistant lecturer Universitat de Barcelona, Villarroel, 170, 08036 Barcelona, Spain. ${ }^{2}$ Associate Nursing Director. Hospital d'Atenció Intermèdia Parc Sanitari Pere Virgili, Esteve Terrades,30, 08023 Barcelona, Spain. ${ }^{3}$ Nurse Unit Manager in Traumatology Unit, Hospital Clinic Barcelona, Villarroel, 170, 08036 Barcelona, Spain. ${ }^{4}$ Vice director of Nursing Care in Complejo Hospitalario de Navarra, Pabellón G. Irunlarrea,3, 31008 Pamplona, Spain. ${ }^{5}$ Consultant Nurse in Research, Hospital Universitario Marqués de Valdecilla, Santander. Pabellón 16 Planta baja. Avenida Valdecilla s/n., 39008 Santander, Spain. ${ }^{6}$ Head of the Care Research Unit, Puerta de Hierro Majadahonda University Hospital. Head of the Nursing and Health Care Research Group, Puerta de Hierro-Segovia de Arana Health Research Institute, Joaquín Rodrigo, 2, 28222 Madrid, Majadahonda, Spain. 7Vice director of Research and Education in Nursing in Hospital Clinic Barcelona, Assistant lecturer Universitat de Barcelona, Escala 1 planta 7. Villarroel 170, 08036 Barcelona, Spain.

Received: 7 January 2020 Accepted: 25 June 2020

Published online: 16 July 2020

\section{References}

1. Patterson C. World Alzheimer Report 2018: The state of the art of dementia report: New frontiers. London: Alzheimer Disease International. Retrieved from: https://www.alz.co.uk/research/world-report-2018. 
2. Antonio AG, Pilar AN, Julio PD, Diego RF, Alba AG, Rodríguez P, Rogelio. Un perfil de las personas mayores en España. In: Indicadores estadísticos básicos, vol. 38. Madrid: Informes Envejecimiento en red n²2; 2019.

3. Lewis F, Karlsberg Schaffer S, Sussex J, et al. The trajectory of dementia in the UK-making a difference: OHE consulting, 2014.

4. Ministerio de sanidad PSEI. Guía de Práctica Clínica sobre la Atención Integral a las Personas con Enfermedad de Alzheimer y otras Demencias. 2011.

5. Farré M, Haro JM, Kostov B, Alvira C, Risco E, Miguel S, et al. Direct and indirect costs and resource use in dementia care: a cross-sectional study in patients living at home. Int J Nurs Stud. 2016;55:39-49. https://doi.org/10. 1016/j.jinurstu.2015.10.012..

6. Lakey L. Counting the cost: caring for people with dementia on hospital wards. Alzheimer's Society; 2009.

7. Robles J, Formiga F. Delirium y fractura de fémur: Básico anticiparse. Revista Española de Geriatría y Gerontología. 2014;49(4):153-4.

8. Mesa-Lampré MP, et al. Puesta en marcha de una unidad de ortogeriatría. Rev esp Cir Orto Traumatol. 2015;59(6):429-38.

9. Mosk, et al. Dementia and delirium, the outcomes in elderly hip fracture patients. Clin Interventions Aging. 2017;12:421-30. https://doi.org/10.2147/ CIA.S115945.

10. Digby R, Lee S, Williams A. People with dementia and nurses in hospitals. J Clin Nursing. 26:1152-71

11. Singh I, Ramakrishna S, Williamson K. The rapid assessment Interface and discharge service and its implications for PwD. Clin Interv Aging Dove Press. 2013;8:1101-8

12. Luppa M, Luck T, Brähler E, König H-H, Riedel-Heller SG. Prediction of institutionalisation in dementia. A systematic review. Dement Geriatr Cogn Disord. Karger Publishers. 2008;26:65-78.

13. Grealish $L$, Jamieson M, Gibson D, Proctor $M$. The interaction between hospital and community-based Services for People with dementia and their Carers. Alzheimer's Australia NSW; 2013.

14. Handley M, Bunn F, Goodman C. Dementia-friendly interventions to improve the care of people living with dementia admitted to hospitals: A realist review. BMJ Open, 2017;7(7). https://doi.org/10.1136/bmjopen-2016015257.

15. Sampson E, White N, Leurent B, Scott S, Lord K, Round J, Jones L. Behavioural and psychiatric symptoms in people with dementia to the acute hospital: prospective cohort study. Br J Psychiatry. 2014;205:189-96.

16. Vieta E, Garriga M, Cardete L, Bernardo M, Lombraña M, Blanch J, et al. Protocolo de Atención a pacientes con agitación psicomotora. Adelphi Targis, S.L.: Barcelona; 2016.

17. Verbeek H, Meyer G, Leino-Kilpi H, Zabalegui A, Hallberg IR, et al. A European study investigating patterns of transition from home care towards institutional dementia care: the protocol of a RightTimePlaceCare study. BMC Public Health. 2012;12:68. https://doi.org/10.1186/1471-2458-12-68.

18. De Mauleon A, Sourdet S, Renom-Guiteras A, Gillette-Guyonnet S, LeinoKilpi $\mathrm{H}$, Karlsson S, et al. Associated factors with antipsychotic use in longterm institutional Care in Eight European Countries: results from the RightTimePlaceCare study. JAMDA. 2014;15(11):812-8.

19. Johnell K, Jonasdottir Bergman G, Fastbom J, Danielsson B, Borg N, Salmi P. Psychotropic drugs and the risk of fall injuries, hospitalisations and mortality among older adults. Int J Geriatr Psychiatry. 2017 Apr;32(4):414-20. https:// doi.org/10.1002/gps.4483.

20. Tsai I, Jeong S, Hunter S. Pain Assessment and Management for Older Patients with Dementia in Hospitals: An Integrative Literature Review. Pain Management Nursing. 2018;19(1):54-71. https://doi.org/10.1016/j.pmn.2017.10.001.

21. Ray C, Ingram V, Cohen-Mansfield J. Systematic review of planned care transitions for persons with dementia. Neurodegener Dis Manag. 2015;5(4): 317-31.

22. Briggs R, Dyer A, Nabeel S, Collins R, Doherty J, Coughlan T, O'Neill DS. Dementia in the acute hospital: the prevalence and clinical outcomes of acutely unwell patients with dementia. QJM. 2017;110(1):33-7. https://doi. org/10.1093/qjmed/hcw114.

23. Gordon SE, Dufour AB, Monti SM, Mattison ML, et al. Impact of a videoconference educational intervention on physical restraint and antipsychotic use in nursing homes: results from the ECHO-AGE pilot study. J Am Med Dir Assoc. 2016;17(6):553-6. https://doi.org/10.1016/j.jamda.2016. 03.002 .

24. Risco E, Zabalegui A, Miguel S, Farré M, Alvira C, Cabrera E. Aplicación del modelo Balance of Care en la toma de decisiones acerca del mejor cuidado para las personas con demencia. Gac Sanit. 2017;31(6):518-23. https://doi. org/10.1016/j.gaceta.2016.07.006.

25. Zabalegui A, Galisteo M, Navarro MM, Cabrera E. INFOSA intervention for caregivers of the elderly, an experimental study. Geriatr Nurs. 2016;37(6): 426-33. https://doi.org/10.1016/j.gerinurse.2016.06.001.

26. Johansson S, Charalambous A, Istomina N, Salanterä S, Sigurdardottir AK, Sourtzi $P$, et al. The quality of recovery on discharge from hospital, a comparison between patients undergoing hip and knee replacement - a European study. J Clin Nurs. 2016;25(17-18). https://doi.org/10.1111/jocn. 13278.

27. Pfeiffer E. A short portable mental status questionnaire for the assessment of organic brain deficit in elderly patients. J Am Geriatr Soc. 1975;23:433-41. https://doi.org/10.1111/j.1532-5415.1975.tb00927.x

28. Librero J, Peiró S, Ordiñana R. Chronic comorbidity and outcomes of hospital care: length of stay, mortality, and readmission at 30 and 365 days. J Clin Epidemiol. 1999;52(3):171-9.

29. Charlson ME, Pompei P, Ales KL, MacKenzie CR. A new method of classifying prognostic comorbidity in longitudinal studies: development and validation. J Chronic Dis. 1987:40:373-83.

30. Urteaga C, Ramos Rl, Atalah E. Validation of global nutrition assessment in elders. Rev Med Chil. 2001;129(8):871-6.

31. Guigoz Y, Vellas B, Garry PJ. Assessing the nutritional status of the elderly: The Mini Nutritional Assessment as part of the geriatric evaluation. Nutr Rev. 1996;54(1 Pt 2):S59-65. https://doi.org/10.1111/j.1753-4887.1996.tb03793.x.

32. Baztán JJ, Pérez del Molino J, Alarcón T, San Cristóbal E, Izquierdo G, Manzarbeitia I. Indice de Barthel: Instrumento válido para la valoración funcional de pacientes con enfermedad cerebrovascular. Rev Esp Geriatr Gerontol. 1993:28:32-40.

33. Mahoney FI, Barthel DW. Functional evaluation: the Barthel index. Md State Med J. 1965:14:61-5.

34. Vilalta-Franch J, Lozano-Gallego M, Hernández-Ferrándiz M, Llinàs-Reglà J, López-Pousa S, López OL. The Neuropsychiatric Inventory. Psychometric properties of its adaptation into Spanish. Rev Neurol. 1999;29(1):15-9.

35. Cummings JL, Mega M, Gray K, Rosenberg-Thompson S, Carusi DA Gornbein J. The neuropsychiatric inventory: comprehensive assessment of psychopathology in dementia. Neurology. 1994;44:2308-14.

36. Alvarez Solar M, De Alaiz Rojo AT, Brun Gurpegui E, Cabañeros Vicente JJ, Calzón Frechoso M, Cosío Rodríguez I, et al. Capacidad funcional de pacientes mayores de 65 años, según el índice de Katz. Fiabilidad del método Aten Primaria. 1992:10(6):812-5.

37. Katz S, Ford AB, Moskowitz RW, Jackson BA, Jaffe MW. Studies of illness in the aged. The index of ADL: a standardized measure of biological and psychological function. JAMA. 1963;185:914-9. https://doi.org/10.1001/jama. 1963.03060120024016

38. García-Soler Á, Sánchez-Iglesias I, Buiza C, Alaba J, Navarro AB, Arriola E, et al. Adaptación y validación de la versión española de la escala de evaluación de dolor en personas con demencia avanzada: PAINAD-Sp. Rev Esp Geriatr Gerontol. 2014;49(1):10-4. https://doi.org/10.1016/j.regg.2013.02. 001.

39. Warden V, Hurley AC, Volicer L. Development and psychometric evaluation of the pain assessment in advanced dementia (PAINAD) scale. J Am Med Dir Assoc. 2003;4(1):9-15.

40. Kim HS. Patient-nurse collaboration in nursing care decision making: American studies. In: International Nursing Research Conference: Global health perspectives. Los Angeles, CA: American Nurses Association and Council of Nurse Researchers; 1991. p. 399.

41. Alvira C, Zabalegui A (dir), Cabrera E (dir). Conocer las reacciones de los cuidadores de pacientes con demencia en un context español y europeo [dissertation on the internet] Castellón: Universitat Jaume l; 2017. Available from https://www.tesisenred.net/bitstream/handle/10803/406134/2017_ Tesis_Alvira\%20Balada_MCarmen.pdf?sequence=1\&isAllowed $=\mathrm{y}$.

42. Given CW, Given B, Stommel M, Collins C, King S, Franklin S. The caregiver reaction assessment (CRA) for caregivers to persons with chronic physical and mental impairments. Res Nurs Health. 1992;15(4):271-83.

43. Mira JJ, Nuño-Solinís R, Guilabert-Mora M, Solas-Gaspar O, Fernández-Cano P, González-Mestre MA, Contel JC, del Río-Cámara M. Development and Validation of an Instrument for Assessing Patient Experience of Chronic Illness Care. Int J Integrated Care. 2016;16(3):13, pp. 1-13. https://doi.org/10. 5334/ijic.2443.

44. Wimo A, Wetterholm AL, Mastey V, Winblad B. Evaluation of the resource utilization and caregiver time in Anti-dementia drug trials - a quantitative 
battery. In: Wimo A, Karlsson G, Jönsson B, Winblad B, editors. The Health Economics of Dementia. London: Wiley's; 1998.

45. Bergstrom N, Braden BJ, Laguzza A, Holman V. The Braden scale for predicting pressure sore risk. Nurs Res. 1987;36:205-10.

46. Luxford C, Axam A, Hasnip F, et al. Improving clinician-carer communication for safer hospital care: a study of the TOP $5^{\prime}$ strategy in patients with dementia. Intern J Qual Health Care. 2015;27(3):175-82.

47. Kitson A, Harvey G, McCormack B. Enabling the implementation of evidence based practice: a conceptual framework. Qual Health Care. 1998;73:149-58.

\section{Publisher's Note}

Springer Nature remains neutral with regard to jurisdictional claims in published maps and institutional affiliations.

Ready to submit your research? Choose BMC and benefit from:

- fast, convenient online submission

- thorough peer review by experienced researchers in your field

- rapid publication on acceptance

- support for research data, including large and complex data types

- gold Open Access which fosters wider collaboration and increased citations

- maximum visibility for your research: over $100 \mathrm{M}$ website views per year

At $\mathrm{BMC}$, research is always in progress.

Learn more biomedcentral.com/submissions 